\title{
The Research on Flow Velocity Control of Hyperthermia Apparatus based on Fuzzy PID Control
}

\author{
YU Fan ${ }^{1, a}$, LIU Minghui ${ }^{2, b^{*}}$, WANG Zhongsheng ${ }^{3, c}$ \\ ${ }^{1,2,3}$ School of Computer Science and Engineering, \\ Xi' an Technological University, Xi' an 710021, P.R.C \\ ayffshun@163.com, b648240689@qq.com, ${ }^{\mathrm{c}} 59483672 @$ qq.com
}

\begin{abstract}
In order to improve the flow velocity control accuracy of hyperthermia apparatus, reduce the overshoot and steady-state time of system, a fuzzy PID control algorithm is proposed in this paper. The algorithm is the composition of fuzzy control and PID control, which makes the system not only has a fast dynamic response, but also has a higher steady-state accuracy. The experimental results show that the fuzzy PID control has a better control effect than the traditional fuzzy control.
\end{abstract}

Keywords-hyperthermia apparatus; flow velocity control; fuzzy PID Control; control accuracy

\section{INTRODUCTION}

Hyperthermia apparatus is a medical equipment for the coelom thermo physical therapy of cancerous effusion. It sends the medication or effusion to coelom at a constant flow velocity, and could kill cancer effectively $^{[1]}$. The flow velocity control is the key in circulatory perfusion of hyperthermia apparatus. At present, the requirements of the flow velocity control not only need higher control accuracy, but also need the shorten transition time of the control system ${ }^{[2]}$. PID control has good steady-state performance, however, its dynamic characteristics are not good enough ${ }^{[3-4]}$. Fuzzy control can response the system in a short time. But fuzzy control has low steady-state accuracy, and exists steady-state error ${ }^{[5-7]}$.

Thus, the combination of fuzzy control and PID control is proposed, it constitutes the fuzzy PID control system. Fuzzy control is used when the error is large, which could make the system rapidly reach the set value. PID control can achieve high accuracy and low steady-state error when the error is small. The control accuracy of the system is improved by adjusting the quantization factor of fuzzy control and the proportional coefficient of PID control. Therefore, the fuzzy PID control has the advantages of the fast response of fuzzy control and the high steady-state accuracy characteristics of PID. In this paper, the fuzzy PID control is used in the hyperthermia apparatus to control the flow velocity of the perfusion. The reliability and validity of the system are verified by MATLAB simulation and experiments ${ }^{[8]}$.

\section{THE DESIGN OF FLOW VELOCITY CONTROL SYSTEM}

A. Switching structure of current velocity control system

In the flow velocity control system, the control algorithm is chosen according the different error value. Firstly, the error e and the change of error ec are input variables could form after comparison between set flow velocity value and the actual flow velocity value. Then, choose the switch selection according to the size of e, that is, the fuzzy control algorithm is selected when e is larger, and the PID control algorithm is selected when e is smaller, and the control variable which obtained is applied to the controlled object. The switch diagram is shown in figure 1.

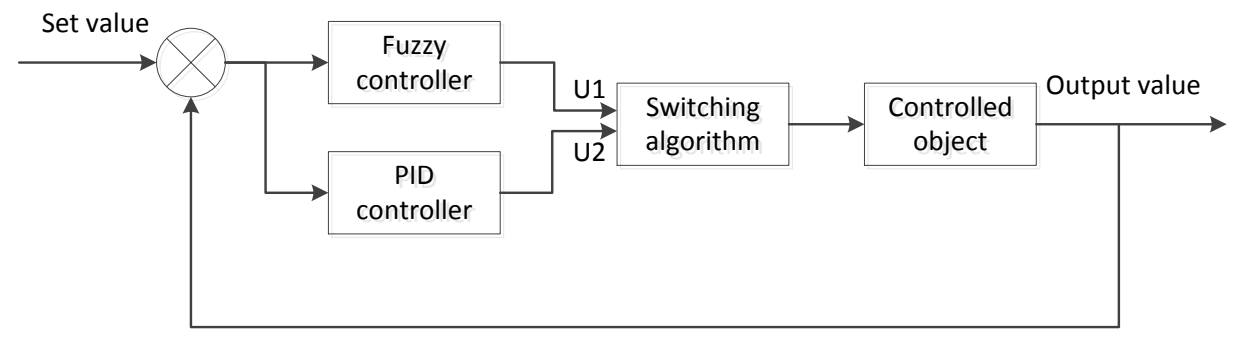

Fig 1. Fuzzy PID control switch

B. The mathematical model of flow velocity control system
In the flow velocity control system, the parameters of the stepper motor are: moment of inertia, phase 
current, viscous damping, etc. According to the various parameters of the stepper motor, the transfer function of the motor is shown in equation (1).

$$
G=\frac{30.5}{S^{2}+108 S+30.5} .
$$

\section{THE DESIGN AND IMPLEMENTATION OF FUZZY PID CONTROL}

\section{A. The design of fuzzy control}

(1) The selection of fuzzy controller

In this paper, the error e and the change of error ec are used as the inputs and the controlled variable $u$ as the output of the fuzzy controller, that is, two inputs and single output.

(2) The definition of fuzzy sets and the domain of input and output

All fuzzy linguistic variables of $\mathrm{e}$, ec and $\mathrm{u}$ are $\{N B, N M, N S, Z O, P S, P M, P B\}$. The domain of fuzzy subsets are respectively: $\{-6,-5,-4,-3,-2,-1,0,1,2,3,4,5,6\},\{-6,-5,-4,-3,-2,-1,0,1,2,3$ $, 4,5,6\},\{-7,-6,-5,-4,-3,-2,-1,0,1,2,3,4,5,6,7\}$. The basic domain of e, ec and u are respectively:[-60,60],[-30,30], $[-49,+49]$. The the quantization factor $K_{e}=6 / 60=0.1$, $\mathrm{K}_{\mathrm{ec}}=6 / 30=0.2$, the scale factor $\mathrm{K}_{\mathrm{u}}=49 / 7=7$.

(3) The selection of fuzzy rules

The conditional statement form of fuzzy control rules is : if e and ec then $u$. The fuzzy control rule is following.

If $\mathrm{E}=\mathrm{NB}$ or $\mathrm{NM}$ and $\mathrm{EC}=\mathrm{NB}$ or $\mathrm{NM}$ Then $\mathrm{u}=\mathrm{PB}$

If $\mathrm{E}=\mathrm{NB}$ or $\mathrm{NM}$ and $\mathrm{EC}=\mathrm{NS}$ or $\mathrm{ZO}$ Then $\mathrm{u}=\mathrm{PB}$

If $\mathrm{E}=\mathrm{PM}$ or $\mathrm{PB}$ and $\mathrm{EC}=\mathrm{PM}$ or $\mathrm{PB}$ Then $\mathrm{u}=\mathrm{NB}$

(4) The selection of membership functions

There are many methods to determine membership functions. And the main is fuzzy statistical method, case method, expert experience method. The commonly used membership functions are triangle, trapezoid, gauss, etc. Triangular membership function is used in this paper.

\section{B. The design of PID control}

PID controller is a linear controller. The linear combination of proportion(P), integration (I), differentiation(D) are constitute controlled variable. The control rule is shown in equation (2).

$$
u(k)=K_{P} e(k)+\frac{K_{P} T}{T_{I}} \sum_{j=0}^{k} e(j)+\frac{K_{P} T_{D} \Delta e(k)}{T}
$$

Among them, $K_{P}$ is proportional coefficient, $T_{I}$ is integral time constant, $\mathrm{T}_{\mathrm{D}}$ is differential time constant. Control output works according to the error, the integral of error and the derivative of error. The adjustment of PID controller is mainly on the parameters tuning method of PID control, which is the selection of $\mathrm{K}_{\mathrm{P}}, \mathrm{T}_{\mathrm{I}}$ and $T_{D}$. In this paper, the stability boundary method joint parameters online is used to adjust the parameters of PID.

\section{SYSTEM SIMULATION}

\section{A. Fuzzy control simulation}

The step response curve is shown in figure 2 . The system reached the steady-state in $4.7 \mathrm{~s}$ and had less overshoot when the set flow velocity is $500 \mathrm{ml} / \mathrm{min}$. In the initialization, when the error is large and fuzzy control system has good dynamic performance, the fuzzy control can achieve the initial steady-state in a relatively short time. 


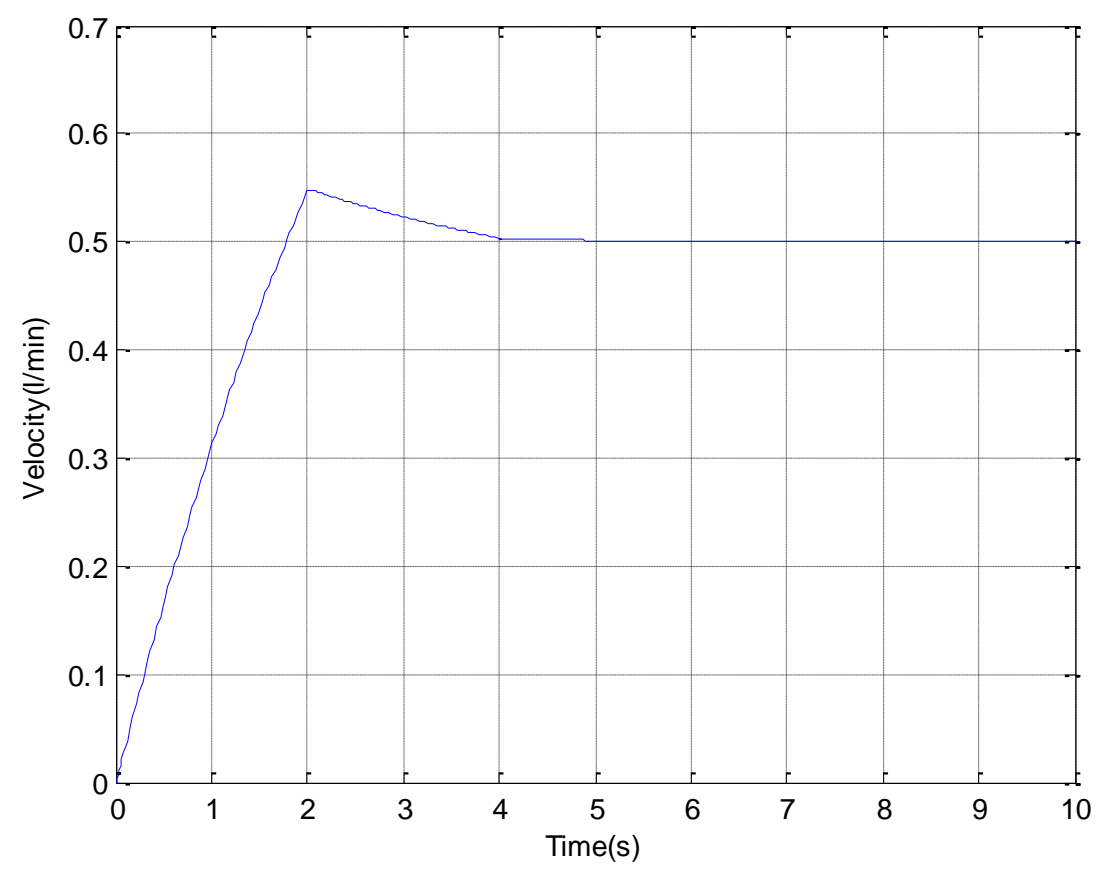

Fig 2. Step response curve of fuzzy control system

\section{B. PID control simulation}

Figure 3 is the step response curve. In figure 3, the system reached the steady-state in $1 \mathrm{~s}$ and had less overshoot when the set flow velocity is $100 \mathrm{ml} / \mathrm{min}$. The simulation proves that there is a good control effect of good steady-state performance and less overshoot while used PID control with e is smaller.

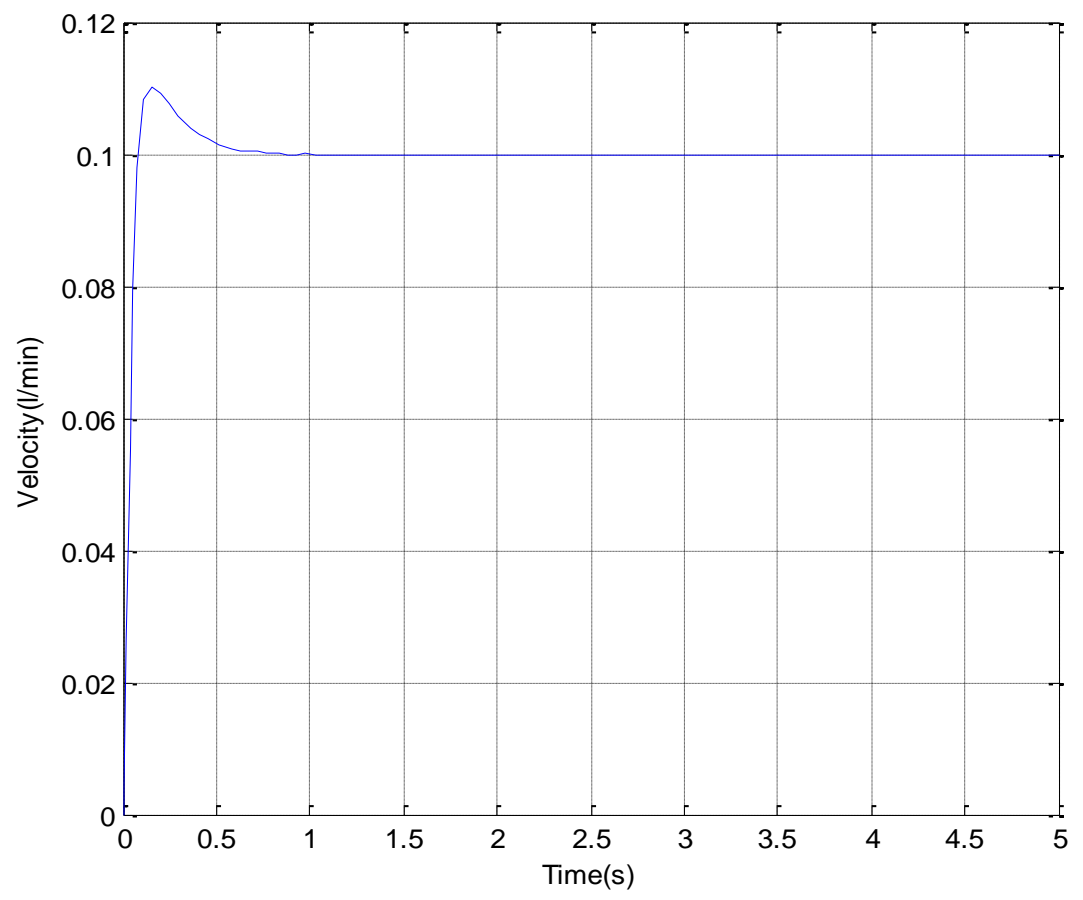

Fig 3. Step response curve of PID control system

\section{Fuzzy PID control simulation}

The step signal input value is set to $500 \mathrm{ml} / \mathrm{min}$, regulate the parameters of fuzzy control and PID control, such as the quantitative factor and proportional coefficient. The step response curve is shown in figure 
4. In figure 4, the system reached the steady-state in $3.7 \mathrm{~s}$ and had less overshoot. For the fuzzy PID dynamic switching system, the method of fuzzy control is used first and the PID control is used last, which not only speed up the system response speed, but also reduce the overshoot and steady-state error.

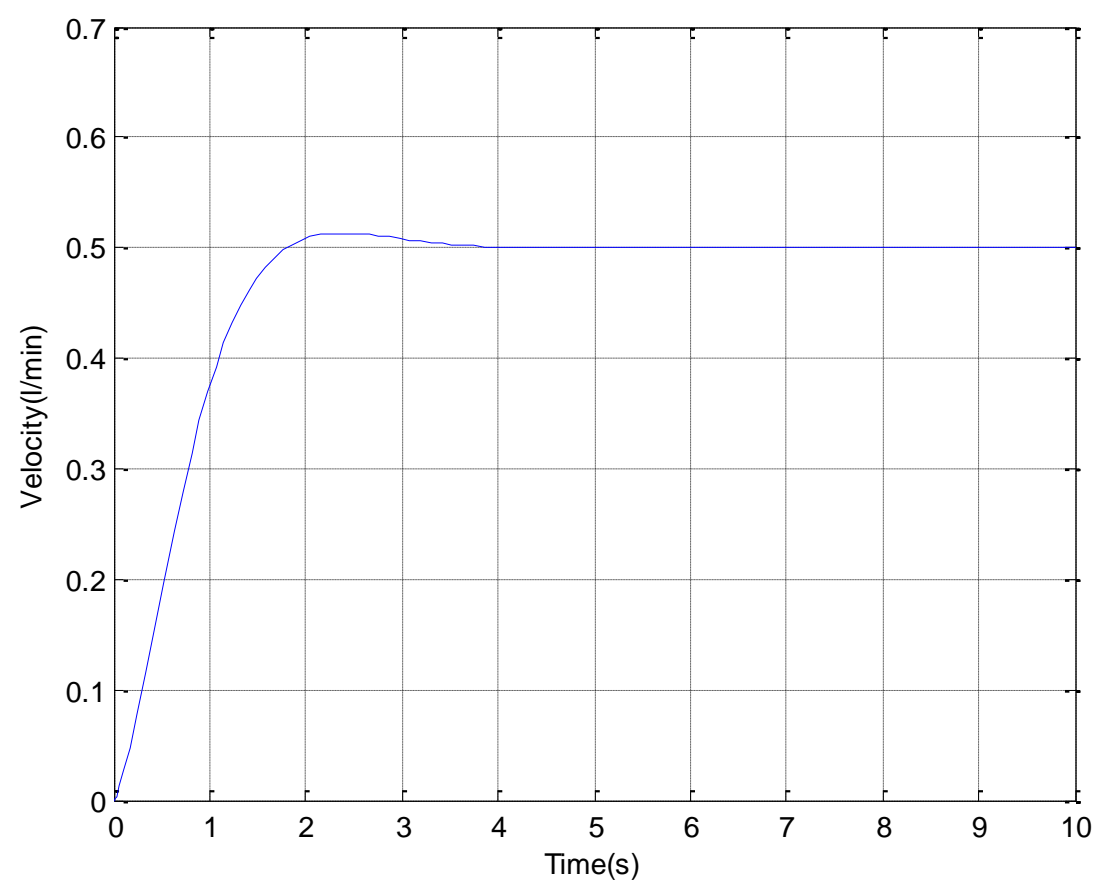

Fig 4. Step response curve of fuzzy PID switching control system

\section{CONCLUSIONS}

The simulation results show that there are some advantages when fuzzy PID control is used in the flow velocity control system of hyperthermia apparatus. There is a relatively short time to achieve the steady-state and less time of adjustment time which used fuzzy control with large error. When the error is small, the PID control is used to reduce the steady-state error and overshoot, moreover, improve the system's steady-state accuracy. The combination of the two algorithms is not only overcomes some of the shortcomings of the traditional control and has good dynamic response and steady-state characteristics, but also improves the control accuracy of the system to some certain extent and make the flow velocity is finer.

\section{REFERENCES}

[1] Huang Jian-lin ,Ye Jian. Application of Fuzzy Self-tuning PID in the Temperature Control System for Tumor Hyperthermia[J].Research Work, 25 (2010) 41-43.
[2] Chen Ming-xin,Tang Ling-feng,Hu Jian.Research on Flow Control System of Pump Based on Fuzzy PID[J].Journal of Xinxiang University, 31 (2014) 36-40.

[3] Qi Lin.Research on Fuzzy and PID Dynamic Switching control Algorithm[D].Beijing Jiaotong University. (2008)

[4] Ying Wu, Hang Jiang, Min Zou.The Research on Fuzzy PID Control of the Permanent agnet Linear Synchronous Motor.Physics Procedia, 24 (2012) 1311-1318.

[5] Liu Xiao-feng,Liu Xiao-hui,Wang Long-shan,etc.Speed synchronization control of dual-motor in large crawler crane based on fuzzy PID control[J]. Journal of Jilin University(Engineering and Technology Edition), 41 (2011) 659-664.

[6] Onur Karasakal, Mujde Guzelkaya, Ibrahim Eksin, et,al.Online tuning of fuzzy PID controllers via rule weighing based on normalized acceleration[J]. Engineering Applications of Artificial Intelligence, 26 (2013) 184-197.

[7] Richa Sharma, K.P.S. Rana, Vineet Kumar.Performance analysis of fractional order fuzzy PID controllers applied to a robotic manipulator[J]. Expert Systems with Applications, 41 (2014) 4274-4289.

[8] Xie Guo-hua, Li Guo-dong,Liu Huan-jin, etc. MATLAB from Zero to Advanced[M]. Beijing University of Aeronautics and Astronautics. (2012) 